\title{
EDUCAÇÃO DO CAMPO NA VOZ DA PESQUISA EM EDUCAC̣ÃO EM CIÊNCIAS
}

\author{
JOSIANE DE SOUZA ${ }^{*}$ \\ https://orcid.org/0000-0001-6652-2977 \\ FERNANDA OSTERMANN" "** \\ https://orcid.org/0000-0002-0594-2174 \\ FLAVIA REZENDE $\|^{* * *}$ \\ https://orcid.org/0000-0002-5739-7905
}

RESUMO: O número expressivo de cursos de licenciatura em educação do campo com ênfase em ciências da natureza, iniciados a partir de 2009 no Brasil, torna relevante a relação entre educação em ciências e educação do campo. Levantamos, na literatura nacional e internacional em educação em ciências, artigos que abordavam a educação do campo e analisamos como era construída discursivamente a aproximação com essa área. Uma análise Bakhtiniana sugeriu discursos híbridos valorizando a realidade local, mas se apropriando do conhecimento científico e/ou do ensino de diferentes maneiras: sem modificação de conteúdos pré-selecionados; com seleção de conteúdos a partir de problemas locais; e com modificações das práticas de ensino. Consideramos os últimos grupos adequados ao que conceituamos como educação científica do campo.

Palavras-chave: Educação em ciências. Educação do campo. Discurso. Análise Bakhtiniana. Hibridismo.

\section{EDUCACIÓN DEL CAMPO EN LA VOZ DE LA INVESTIGACIÓN EN EDUCACIÓN CIENTIFICA}

RESUMEN: El número expresivo de carreras de licenciatura en educación del campo con énfasis en ciencias de la naturaleza, que se iniciaron a partir de 2009 en Brasil, hace relevante la relación entre educación científica y educación del campo. Buscamos, en la literatura nacional e

\begin{abstract}
*Doutoranda do Programa de Pósgraduação em Ensino de Física da Universidade Federal do Rio Grande do Sul (UFRGS). Professora efetiva do Instituto Federal Sul-rio-grandense (IFSUL). Grupo de Pesquisa e Inovação Didática em Ensino de Física sob a Perspectiva Sociocultural. E-mail:<josianesouza@ifsul.edu.br $>$.

* *Doutora em Física pela Universidade Federal do Rio Grande do Sul (UFRGS). Professora Titular membro permanente do Programa de Pós-Graduação em Ensino de Física da Universidade Federal do Rio Grande do Sul (UFRGS), Porto Alegre, Rio Grande do Sul, Brasil. Líder do Grupo de Pesquisa e Inovação Didática em Ensino de Física sob a Perspectiva Sociocultural. E-mail: < fernanda.ostermann@ufrgs.br >

* * Doutora em Educação pela Pontifícia Universidade Católica do Rio de Janeiro (PUC-Rio). Professora colaboradora do Programa de Pós-Graduação em Ensino de Física da Universidade Federal do Rio Grande do Sul (UFRGS), Porto Alegre, Rio Grande do Sul, Brasil.. Grupo de Pesquisa e Inovação Didática em Ensino de Física sob a Perspectiva Sociocultural. E-mail:< flaviarezende@uol.com.br > .
\end{abstract}

\footnotetext{
' Instituto Federal Sul-rio-grandense, Santana do Livramento, RS - Brasil.

" Universidade Federal do Rio Grande do Sul, Instituto de Física, Porto Alegre, RS - Brasil
} 
internacional en educación científica, artículos que abordaban la educación del campo y analizamos cómo se construía discursivamente la aproximación con el área. Un análisis bajtiniano sugirió discursos híbridos que valoran la realidad local, pero que se apropian del conocimiento científico y/o de la enseñanza de diferentes maneras: sin modificación de contenidos preseleccionados; con selección de contenidos a partir de problemas locales; y con modificación de las prácticas de enseñanza. Consideramos los últimos grupos adecuados a lo que conceptualizamos como educación científica del campo. Palabras clave: Educación científica. Educación del campo. Discurso. Análisis Bakhtiniano. Hibridismo.

\section{RURAL EDUCATION FROM THE PERSPECTIVE OF RESEARCH IN SCIENCE EDUCATION}

ABSTRACT: The significant number of undergraduate courses in rural education, initiated in 2009, in Brazil, with emphasis on natural sciences makes relevant the relation between science education and rural education. We searched for articles in national and international science education journals that addressed rural education and analyzed how they approached it. A Bakhtinian analysis suggested that all of them constructed hybrid discourses valuing local reality, but in different ways, in relation to the appropriation of scientific knowledge and/or science teaching: without modification of pre-selected content; with selection of content based on local problems and with modifications of science education practices. We consider the last groups adequate to what we define as scientific rural education.

Keywords: Science education. Rural education. Discourse. Bakhtinian analysis; Hybridism. 


\section{INTRODUÇÃO}

Desde a criação do Programa de Apoio à Formação Superior em Licenciatura do Campo (Procampo), em 2009, mais de 40 cursos de licenciatura foram iniciados no Brasil, sendo as ciências da natureza uma das ênfases mais recorrente. Os projetos educacionais fomentados por esse programa estão intrinsecamente ligados à perspectiva defendida por vários movimentos sociais do campo, responsáveis pela luta e pelo lançamento do Procampo. Essa perspectiva engloba não apenas a luta por acesso à educação, mas também à terra, pela reforma agrária, pelo direito ao trabalho, à cultura, à soberania alimentar e aos territórios dos povos do campo, questões que, em geral, não são abordadas ao longo da formação dos docentes, nem pelo currículo de ciências. Tais questões envolvem desafios pedagógicos, metodológicos e curriculares. Neste trabalho nos voltamos para as reflexões a respeito desses desafios que vêm sendo construídas no âmbito da pesquisa em educação em ciências. Para tal, tomamos como ponto de partida a identificação de discursos acadêmicos produzidos a partir de 2009, nos periódicos nacionais e internacionais dessa área.

Abordamos inicialmente circunstâncias sociais e políticas do Brasil que levaram à criação de legislações para constituição da educação do campo e das licenciaturas em educação do campo, compondo assim o contexto extraverbal dos discursos produzidos pelos pesquisadores. Tendo como referência conceitos da filosofia da linguagem de Bakhtin (2011), consideramos os artigos enquanto enunciados a serem analisados, no sentido de compreender como vem sendo construída discursivamente a aproximação da educação em ciências com a educação do campo.

\section{DA EDUCAĈ̣̃O RURAL ÀS LICENCIATURAS EM EDUCAĈ̣̃O DO CAMPO}

O Brasil traz, ao longo de sua história, marcas da desvalorização da população oriunda do campo, que podem ser percebidas, de um modo geral, pela ausência de políticas públicas voltadas para esse grupo social, incluindo-se aí políticas educacionais. A recente cunhagem da expressão educação do campo e as políticas públicas implementadas em prol dessa causa são, em grande parte, resultado da história da luta dos povos do campo. Tentando fazer uma retrospectiva da educação do campo, entendemos o processo brasileiro de industrialização, após a crise mundial de 1929, como determinante, ao fazer com que grande parte da população rural fosse deslocada para as cidades, formando uma massa de trabalhadores disponíveis para o capital (VENDRAMINI, 2013). Dessa forma, criou-se a ideia de dois Brasis, um moderno e industrializado, representado pelos centros urbanos, e outro atrasado, representado pelas zonas rurais. Nos documentos oficiais brasileiros a primeira menção à educação rural aparece na Constituição Federal de 1934, em que, no artigo 121, afirma-se que "procurar-se-á fixar o homem no campo, cuidar de sua educação rural, e assegurar ao trabalhador nacional a preferência na colonização e aproveitamento das terras públicas” (BRASIL, 1934). Esta citação deixa claro o objetivo educacional de manter trabalhadores no campo, desempenhando atividades agrícolas. No Decreto de Lei nº 9613 de 1946, acerca 
da base organizacional do ensino primário, surge a expressão "educação agrícola", definida como um ramo de ensino até o segundo grau, destinado essencialmente à preparação profissional técnica dos trabalhadores da agricultura.

Com a instauração do Regime Militar em 1964, as políticas públicas para o povo do campo foram sucateadas e transformadas em políticas de subordinação do campo à cidade e ao sistema capitalista financeiro. A agricultura familiar, segundo Fernandes (2008), que fomenta a identidade do campo e melhora as condições de vida e saúde dos campesinos, foi preterida em função do agronegócio, que, por meio da concentração econômica, impõe a racionalidade do capital sobre o campo, utiliza de forma exagerada insumos agroquímicos artificiais e agrotóxicos, mecaniza o trabalho do campo e desnacionaliza progressivamente o setor agrícola através do controle da agricultura pelo capital financeiro articulado a grandes empresas internacionais (HAGE, 2014). Assim, o modelo econômico adotado pelos governos militares modernizou a agricultura capitalista, o que aumentou a produtividade e, contraditoriamente, o desemprego que levou ao aumento do número de trabalhadores sem-terra.

Nos anos de 1980 o Brasil passava por intensa luta por redemocratização e o mundo inteiro acompanhava movimentos que lutavam pela paz mundial, pela preservação do meio ambiente e pelos direitos humanos. Logo, a educação ganhou papel de destaque na manutenção ou transformação da sociedade. Os movimentos sociais foram engrossados pelos trabalhadores rurais prejudicados pelas medidas tomadas pelo governo militar e a luta pela terra e pela reforma agrária foi intensificada.

Em 20 de Dezembro de 1996 é sancionada a Lei 9.394 - Diretrizes e Bases da Educação (LDB), que, juntamente com as diretrizes curriculares estabelecidas, implicam o respeito às diferenças e à política de igualdade, passando a associar à qualidade da educação a perspectiva da inclusão. No art. 28 da LDB, é mencionada a necessidade de adequação dos sistemas de ensino à vida rural: "[..] na oferta da educação básica rural, os sistemas de ensino promoverão as adaptações necessárias para a adequação às peculiaridades da vida rural e de cada região [...]" (BRASIL, 1996, p. 10). Mas, apesar do reconhecimento da singularidade do campo, a educação rural não foi definida por esse documento, ficando relegada à livre interpretação. Uma consulta ao Dicionário da Educação do Campo (RIBEIRO, 2012) revela como definição para a educação rural, a que é destinada aos camponeses, ou seja, àqueles que residem e trabalham nas zonas rurais e recebem os menores rendimentos por seu trabalho. Segundo a autora, quando há uma escola na área rural ela oferta educação na mesma modalidade das escolas da área urbana, quer dizer, "que não relaciona o estudo feito na escola ao trabalho produtivo feito na terra” (p. 296), não havendo tentativas de adequar as escolas rurais às características dos camponeses: "nessa escola apenas se estuda, e este estudo nada tem a ver com o trabalho que o camponês desenvolve com a terra” (Idem, p. 296).

Em 1998, na $1^{\circ}$ Conferência Nacional Por uma Educação do Campo nasce o Movimento por uma Educação do Campo, que, apoiado por outros movimentos sociais do campo, busca denunciar o silenciamento por parte dos órgãos governamentais, dos núcleos de financiamento, dos centros de pesquisa, e dos estudiosos acerca das questões que envolvem o campo e sua educação. Esse debate e a luta iniciada produziram reflexos nas políticas públicas, como o art. $2^{\circ}$ 
da Resolução CNE/CEB n. 1 de 3 de abril de 2002 (BRASIL, 2002), que elevou a um outro patamar as escolas do campo, definindo para a modalidade e para a população do campo, uma nova identidade, vinculada

[...] às questões inerentes à sua realidade, ancorando-se na temporalidade e saberes próprios dos estudantes, na memória coletiva que sinaliza futuros, na rede de ciência e tecnologia disponível na sociedade e nos movimentos sociais em defesa de projetos que associem as soluções exigidas por essas questões à qualidade social de vida coletiva do país. (p. 1)

A partir dessa resolução, a educação rural dá espaço, definitivamente, à educação do campo, deixando de ser uma cópia dos modelos "urbanocentrados" (ARROYO et al, 2004) e não sendo apenas uma nova modalidade de educação rural, ou uma variação dessa, mas uma concepção totalmente diferente, que passa a gerar novas medidas políticas e de investimento.

Com base nessa nova concepção da educação do campo, foram criadas, no segundo governo Lula, em 2009, políticas públicas que dessem suporte ao seu desenvolvimento, como o Programa de Apoio à Formação Superior em Licenciatura do Campo (Procampo). Esse programa autorizava destinação de recursos financeiros às instituições públicas de ensino superior para ampliação do acesso e permanência dos estudantes de baixa renda, estudantes oriundos do campo, grupos étnicos diversificados e profissionais da educação sem formação específica de nível superior. Para concorrerem ao financiamento, os projetos seriam, particularmente, aqueles voltados à oferta de cursos de formação inicial ou continuada de professores indígenas, professores de educação do campo e professores afrodescendentes ou que atuassem na educação étnico-racial, no âmbito da educação básica.

Entre os critérios exigidos pelo primeiro edital do Procampo, lançado em 2010, os projetos deveriam prever: a criação de condições teóricas, metodológicas e práticas para que os educadores atuassem na construção e reflexão do projeto político-pedagógico das escolas do campo; a organização curricular em regime de alternância; a formação por áreas de conhecimento previstas para a docência multidisciplinar (Linguagens e Códigos; Ciências Humanas e Sociais; Ciências da Natureza e Matemática; Ciências Agrárias); e consonância com a realidade social e cultural específica das populações do campo.

Foram aprovados projetos de 33 instituições de ensino, totalizando 3358 novas vagas em cursos de licenciatura em educação do campo. Em dezembro de 2012, a Secretaria de Educação Continuada, Alfabetização e Diversidade (Secad) apresentou as 44 propostas institucionais aprovadas para implementar cursos de licenciatura em educação do campo. Dessas, 32 ofereciam habilitações na área das Ciências da Natureza. Cada um dos cursos dispunha, em média, de 60 vagas por habilitação a cada ano, o que configurava em torno de 1900 novos alunos de licenciatura em educação do campo cursando habilitações em Ciências da Natureza ou relacionadas a essa área. Consideramos que esse número expressivo e a relação desses cursos com o ensino de ciências tornam essas licenciaturas contextos relevantes do ponto de vista da pesquisa em educação em ciências e da reflexão sobre formação dos docentes que vão atuar nesses cenários. 
Originalmente, o currículo das licenciaturas em ciências era pautado por uma visão de mundo que considerava a ciência neutra, dissociada das outras esferas da sociedade e vista como uma forma autônoma de cultura que se refletia nos currículos da educação básica. Segundo Krasilchik (2000), esse currículo era moldado de forma tradicionalista e racionalista, em que o objetivo dos docentes deveria ser apenas a transmissão de informações através da apresentação organizada do conteúdo, visando a aquisição de conhecimentos pelos alunos. O currículo de ciências, especificamente das escolas rurais, seguiram por muito tempo esses moldes, sem ter como pauta o diálogo com questões sociais, culturais, políticas e econômicas relacionadas com o campo, contradizendo, assim, a própria resolução n. 1 de 2002, que associa a identidade da educação do campo às questões inerentes à realidade da população do campo. Essa breve retomada histórica da educação do campo servirá como contexto extraverbal da análise que pretendemos realizar de artigos de pesquisa em educação em ciências que abordam a educação do campo, no sentido de compreender como é construída discursivamente a aproximação com essa área.

\section{CAMINHOS TEÓRICO-METODOLÓGICOS}

Neste estudo, temos como objeto de pesquisa o discurso acadêmico da educação em ciências que se relaciona de algum modo com a educação do campo, presente em artigos publicados em periódicos nacionais e internacionais no período de 2009 a 2018. Buscamos assim suporte em conceitos da filosofia da linguagem, desenvolvida pelo filósofo russo Mikhail Bakhtin (1895-1975), para realizar a análise dos artigos. Com Bakhtin (2009), concordamos que o discurso não emerge de atos isolados de fala individual e nem do sistema abstrato de regras gramaticais da língua, mas é construído na interação viva das forças sociais e constituído por ideologias que permeiam a vida dos sujeitos. O discurso é pensado, moldado e proferido de acordo com os propósitos da esfera em que é produzido e a relação discursiva se dá através do ato da enunciação, pelo locutor, e da compreensão do enunciado, pelo ouvinte (VOLOSHINOV, 1930).

Os discursos escolhidos pelo falante, apesar de próprios, são, como defende Bakhtin (2009), povoados pelas palavras de outras pessoas, que são transmitidas em graus diversos de fidelidade e imparcialidade, determinando assim, um maior ou menor grau de dialogia com as ideias e ideologias de outros sujeitos. Para Bakhtin (2015), o processo de formação ideológica do homem é um processo de assimilação seletiva das palavras dos outros. Ou seja, estruturamos concepções ideológicas nos apropriando de discursos, reinterpretando signos e moldando significados que irão servir aos nossos propósitos. Assim, o discurso, para Bakhtin (2015), é produzido por meio de um diálogo entre a voz de quem fala, com outras vozes organizadas socialmente. O conceito de voz, neste caso, não significa apenas a expressão oral, mas também a escrita e abrange as impressões, o conhecimento adquirido ao longo da vida, as visões do mundo do sujeito e a perspectiva que assume sobre o mundo, ligada à ideologia dos grupos aos quais pertence.

Na perspectiva Bakhtiniana o discurso é proferido por meio de enunciados, considerados pelo autor como a real unidade da comunicação discursiva (BAKHTIN, 2011). O enunciado possui algumas características: conteúdo 
temático, estilo verbal, construção composicional, responsividade, direcionalidade e conclusibilidade. O conteúdo temático está associado ao domínio de sentido do texto e o estilo de verbal corresponde aos procedimentos de acabamento de um enunciado, como recursos lexicais, fraseológicos e gramaticais da língua utilizados para elaborá-lo. A construção composicional está relacionada ao tipo de estruturação ou organização do enunciado.

Essas características e respectivos elementos estão indissoluvelmente relacionados ao todo do enunciado, sendo que todos são marcados pela especificidade de uma dada esfera da comunicação verbal. Já a delimitação do enunciado Bakhtiniano é dada pela alternância dos sujeitos do discurso, que ocorre porque o falante dá indícios de que está terminando a fala (conclusibilidade) e, assim, suscita resposta do outro. Ou, no caso de enunciados escritos, o autor termina seu artigo, texto, livro, dando a oportunidade para que o leitor possa fazer suas considerações. Bakhtin (2011) denomina cada enunciação de réplica e afirma que cada réplica dentro de um diálogo, por mais breve e fragmentária que seja, possui conclusibilidade.

Todo enunciado, para se constituir, necessita de um falante, que o enuncia, e de um ouvinte, que o interpreta. Essa interpretação é ativamente responsiva. A oposição, concordância, objeção, execução, etc., vêm de uma atitude responsiva ao enunciado, ou seja, nenhuma interpretação de enunciado é livre de juízo de valor ou posicionamento do ouvinte. Chegamos assim à característica do enunciado denominada de responsividade. $\mathrm{O}$ enunciado tem caráter responsivo ao ser proferido pelo falante e interpretado pelo ouvinte, responsividade entre o falante e o ouvinte. Para Bakhtin (2011), cada enunciado é um elo na corrente complexamente organizada de outros enunciados, ou seja, cada enunciado responde a outros enunciados que já foram proferidos anteriormente

Ao mesmo tempo, o enunciado é elaborado pensando-se nas possíveis respostas que virão do ouvinte. Assim, o falante está direcionando-o a certo destinatário suposto que também pertence a uma determinada esfera da atividade humana. A direcionalidade é, portanto, o componente que faz com que o enunciado exista, se constitua, pois, ao direcionar seu discurso para determinado ouvinte, o falante molda o enunciado pensando nas questões de responsividade, estilo, construção e gênero adequadas ao seu destinatário. Para além de sua relação imediata com os outros participantes do diálogo, o enunciado se relaciona irremediavelmente ao momento histórico, político, econômico, e da vivência do falante, das leituras por ele realizadas, que, entre outros, compõem o contexto extraverbal do enunciado e ajudam a compreender o processo de construção discursiva.

O enunciado também pode ser construído por meio de processos complexos de assimilação de discursos que não se dão pela simples coexistência de linguagens, mas pela criação, a partir de linguagens diferentes, de uma nova forma de enunciar. Esse processo é denominado por Bakhtin (2015) de hibridismo e é caracterizado por "um enunciado que pertence, pelos seus marcadores gramaticais (sintáticos) e composicionais, a um só falante, mas que realmente contém misturados em seu interior dois enunciados, duas maneiras de falar, dois estilos, duas 'linguagens', dois sistemas de crença semânticos e axiológicos” (p. 84) sem que haja limite formal, composicional e sintático entre eles.

No presente estudo, realizamos uma análise Bakhtiniana de artigos da 
área de educação em ciências que abordam a educação do campo, publicados em periódicos nacionais e internacionais. Foram selecionamos todos os periódicos avaliados no quadriênio 2013/2016 pelo sistema Qualis/CAPES e classificados nos estratos A1 e A2, voltados para a área de educação em ciências (Apêndice A) que faziam parte dos estratos das áreas de Educação e Ensino. A checagem do pertencimento à área de educação em ciências foi feita a partir da descrição apresentada no site de cada publicação.

Para realizar a análise, foi utilizado um dispositivo analítico (VENEU et al, 2015) proposto especificamente para análises Bakhtinianas do discurso, composto pelas quatro etapas descritas a seguir, já articuladas ao objetivo deste trabalho.

(1) Identificação do enunciado: como o Procampo foi lançado em 2009, restringimos nossa busca ao período de Janeiro de 2009 até Maio de 2018, utilizando os extratores educação do campo e educação rural nos periódicos nacionais, educación del campo e educación rural, nos periódicos de língua espanhola e rural education, nos periódicos de língua inglesa. Utilizamos diferentes possibilidades de extratores, pois não conhecíamos os termos usados na literatura internacional para significar educação do campo. Consideramos cada artigo encontrado como um enunciado a ser analisado, visto que, por ser um discurso escrito, a noção de conclusibilidade se dá pela conclusão do artigo.

(2) Leitura preliminar do enunciado: o objetivo desta etapa é estabelecer o primeiro contato com os enunciados no sentido de identificar preliminarmente seus elementos linguísticos e fazer uma articulação prévia entre o material linguístico, as questões de pesquisa e os conceitos Bakhtinianos. Realizamos uma leitura prévia dos enunciados e elencamos os conceitos que nos auxiliariam a compreender como os autores relacionavam a educação em ciências com a educação do campo. Valorizamos os conceitos de responsividade, voz, dialogismo e hibridismo para buscar compreender com quais perspectivas os autores escolheram dialogar, a que vozes os artigos são responsivos, estabelecendo aproximações ou afastamentos no sentido de construírem uma reflexão (sua própria voz) sobre a relação da educação em ciências com a educação do campo. O conceito de hibridismo foi considerado igualmente importante no sentido de nos permitir perceber se estaria sendo levada em conta mais de uma perspectiva em propostas dos autores a respeito de como o ensino de ciências deveria ser desenvolvido no âmbito da educação do campo.

No período pesquisado, encontramos cinco artigos nacionais da área de educação em ciências que incluíam educação do campo e nenhum artigo que incluísse educação rural no título, palavras-chave ou resumo. Porém, após leitura na íntegra desses artigos, inferimos que dois artigos utilizavam as escolas do campo apenas como contexto para aplicação de propostas pré-concebidas sem serem levadas em consideração particularidades da educação do campo. Consideramos assim, um conjunto de três artigos (Quadro 1) como objeto para a análise a ser realizada. 
Quadro 1. Artigos selecionados nos periódicos nacionais

\begin{tabular}{|l|l|l|l|}
\hline \multicolumn{1}{|c|}{ Título do Artigo } & \multicolumn{1}{|c|}{ Autorles) } & Ano & Periódico \\
\hline $\begin{array}{l}\text { Currículo de Ciências: } \\
\text { professores e escolas } \\
\text { do campo }\end{array}$ & $\begin{array}{l}\text { Lívia de Rezende } \\
\text { Cardoso e Maria Inez } \\
\text { de Oliveira Araújo }\end{array}$ & 2012 & $\begin{array}{l}\text { Revista Ensaio } \\
\text { Pesquisa em Educação } \\
\text { em Ciências }\end{array}$ \\
\hline $\begin{array}{l}\text { A pesquisa como } \\
\text { possibilidade de } \\
\text { ressignificação das } \\
\text { práticas de ensino na } \\
\text { escola no/do campo }\end{array}$ & $\begin{array}{l}\text { Rosenilde Nogueira } \\
\text { Paniago, Simone } \\
\text { Albuquerque da Rocha } \\
\text { e Josenilde Nogueira } \\
\text { Paniago }\end{array}$ & 2014 & $\begin{array}{l}\text { Revista Ensaio } \\
\text { Pesquisa em Educação } \\
\text { em Ciências }\end{array}$ \\
\hline $\begin{array}{l}\text { Ensino de Ciências: } \\
\text { uma discussão } \\
\text { na perspectiva da } \\
\text { educação do campo }\end{array}$ & $\begin{array}{l}\text { Lucinete Gadelha da } \\
\text { Costa, Monica Silva } \\
\text { Aikawa e Ingrid da Silva } \\
\text { Cunha }\end{array}$ & 2014 & $\begin{array}{l}\text { Areté Revista } \\
\text { Amazônica de Ensino } \\
\text { de Ciências }\end{array}$ \\
\hline
\end{tabular}

Fonte: Autoria própria

No âmbito internacional, encontramos 19 artigos que incluíam ruraleducation e nenhum artigo que incluísse educación del campo e educación rural no título, palavraschave ou resumo. Após leitura na íntegra de todos os artigos, desconsideramos 8 artigos que utilizavam o campo apenas como contexto de aplicação de propostas ou que eram voltados para a agricultural education, equivalente ao que chamamos no Brasil de educação agrícola, uma modalidade de educação realizada no âmbito do ensino técnico e não do ensino básico, como a educação do campo. Os 11 artigos (Quadro 2) que compõem o conjunto a ser analisado foram publicados em um número especial da Cultural Studies of Science Education. 
Quadro 2. Artigos selecionados nos periódicos internacionais

\begin{tabular}{|c|c|c|c|}
\hline Título do Artigo & Autor(es) & Ano & Periódico \\
\hline $\begin{array}{l}\text { Towards multidimensional } \\
\text { approaches to research on rural } \\
\text { science education }\end{array}$ & $\begin{array}{l}\text { Eleanor Abrams e } \\
\text { Michael Middleton }\end{array}$ & 2016 & $\begin{array}{l}\text { Cultural Studies of } \\
\text { Science Education }\end{array}$ \\
\hline $\begin{array}{l}\text { Oral traditions: a contextual } \\
\text { framework for complex science } \\
\text { concepts-laying the foundation } \\
\text { for a paradigm of promise in rural } \\
\text { science education }\end{array}$ & $\begin{array}{l}\text { Leanne M. Avery e } \\
\text { Btyan J. Hains }\end{array}$ & 2016 & $\begin{array}{l}\text { Cultural Studies of } \\
\text { Science Education }\end{array}$ \\
\hline $\begin{array}{l}\text { High school biology evolution } \\
\text { learning experiences in a rural } \\
\text { context: a case of and for cultural } \\
\text { border crossing }\end{array}$ & Lisa A. Borgerding & 2016 & $\begin{array}{l}\text { Cultural Studies of } \\
\text { Science Education }\end{array}$ \\
\hline $\begin{array}{l}\text { Rural science education as social } \\
\text { justice }\end{array}$ & Karen Eppley & 2016 & $\begin{array}{l}\text { Cultural Studies of } \\
\text { Science Education }\end{array}$ \\
\hline $\begin{array}{l}\text { Advancing educational diversity: } \\
\text { antifragility, standardization, } \\
\text { democracy, and a multitude os } \\
\text { education options }\end{array}$ & $\begin{array}{l}\text { Michael W. P. } \\
\text { Fortunato }\end{array}$ & 2016 & $\begin{array}{l}\text { Cultural Studies of } \\
\text { Science Education }\end{array}$ \\
\hline $\begin{array}{l}\text { Re-inhabiting place in } \\
\text { contemporary rural communities: } \\
\text { Moving toward a critical pedagogy } \\
\text { of place }\end{array}$ & $\begin{array}{l}\text { Lacey D. Huffling, } \\
\text { Hiede B. Carlone e } \\
\text { Aerin Banvides }\end{array}$ & 2016 & $\begin{array}{l}\text { Cultural Studies of } \\
\text { Science Education }\end{array}$ \\
\hline $\begin{array}{l}\text { The cognitive relevance of } \\
\text { Indigenous and rural: Why is it } \\
\text { critical to survival? }\end{array}$ & $\begin{array}{l}\text { Karim-Aly S. Kassam, } \\
\text { Leanne M. Avery e } \\
\text { Morgan L. Ruelle }\end{array}$ & 2016 & $\begin{array}{l}\text { Cultural Studies of } \\
\text { Science Education }\end{array}$ \\
\hline $\begin{array}{l}\text { Pratical resources for critical } \\
\text { science education in rural } \\
\text { Appalachia }\end{array}$ & Ann Kingsolver & 2016 & $\begin{array}{l}\text { Cultural Studies of } \\
\text { Science Education }\end{array}$ \\
\hline $\begin{array}{l}\text { Gateway to understanding: } \\
\text { Indigenous ecological activism } \\
\text { and education in urban, rural, and } \\
\text { remote contexts }\end{array}$ & $\begin{array}{l}\text { Gregory Lowan- } \\
\text { Trudeau }\end{array}$ & 2016 & $\begin{array}{l}\text { Cultural Studies of } \\
\text { Science Education }\end{array}$ \\
\hline $\begin{array}{l}\text { Oral traditions, changing rural } \\
\text { landscapes, and science education }\end{array}$ & Sarah Riggs Stapleton & 2016 & $\begin{array}{l}\text { Cultural Studies of } \\
\text { Science Education }\end{array}$ \\
\hline $\begin{array}{l}\text { Laerning in and about rural } \\
\text { places: Connections and tensions } \\
\text { between students' everyday } \\
\text { experiences and environmental } \\
\text { quality issues in theis community }\end{array}$ & $\begin{array}{l}\text { Heather Toomey } \\
\text { Zimmerman e } \\
\text { Jennifer L. Weible }\end{array}$ & 2016 & $\begin{array}{l}\text { Cultural Studies of } \\
\text { Science Education }\end{array}$ \\
\hline
\end{tabular}

Fonte: Autoria própria 
(3) Descrição do contexto extraverbal: a partir da leitura preliminar dos artigos e da articulação prévia entre o objeto da pesquisa e os conceitos Bakhtinianos, entendemos que os elementos históricos e sociais trazidos nas seções introdutórias do presente artigo possam ser considerados contexto extraverbal dos artigos nacionais sobre educação do campo. Em relação ao contexto extraverbal internacional, o recurso utilizado foi procurar em cada artigo, menção a políticas públicas, situação social da comunidade e outras informações do contexto local que pudessem estar moldando os enunciados dos autores sobre a educação rural.

(4) Análise do enunciado: consistiu em articular os elementos linguísticos (estilo, construção composicional, conteúdo temático, relação com o falante e outros participantes, conclusibilidade), o contexto extraverbal e os conceitos Bakhtinianos aos objetivos do estudo. As próximas seções são dedicadas à análise discursiva dos artigos selecionados, com objetivo de compreender como os autores constroem a aproximação entre a educação em ciências e a educação do campo/rural.

\section{A EDUCAÇÃO DO CAMPO (OU RURAL) NA VOZ DA PESQUISA EM EDUCAÇÃO EM CIÊNCIAS}

\section{A educação do campo nos artigos nacionais da área de educação em ciências}

Embora a educação científica constitua a base curricular de muitos cursos de licenciatura da educação do campo desde 2009, é incipiente o número de estudos na literatura especializada da área de educação em ciências que problematizem a educação científica e a formação docente nesse contexto. Os artigos nacionais levantados apresentam diferentes perspectivas de encontro entre as duas áreas: enquanto Cardoso e Araújo (2012) buscam descobrir como os professores do campo escolhem os conteúdos de ciências que serão trabalhados nas escolas campesinas; Paniago et al (2014) buscam, através da pesquisa como ferramenta pedagógica, romper com o trabalho escolar desvinculado do ambiente do aluno, de seus saberes e cultura; Costa et al (2014) buscam refletir sobre o processo de ensino de ciências e sua interligação com as peculiaridades da escola do campo.

Considerando o currículo como uma ferramenta de controle que vai além dos conteúdos e é regida por relações de poder, Cardoso e Araújo (2012) entendem que o currículo de ciências deve ser continuamente repensado e questionado. Para as autoras, a disciplina escolar ciências sempre teve a ciência ocidental moderna como referência no processo de seleção de saberes legítimos, desprezando-se assim, a cultura popular por meio de sua inferiorização. As autoras trazem a voz do movimento "Por uma Educação do Campo", que afirma que a escola do campo é compreendida como um lugar em que se produz o conhecimento a partir da relação direta com a cultura que os sujeitos estabelecem entre si e com o meio onde vivem (CARDOSO e ARAÚJO, 2012). Também se apropriam da voz de Roseli Caldart ${ }^{1}$ ao assumirem que a escola do campo é um tipo diferente de escola, que ajuda no fortalecimento dos povos do campo como sujeitos sociais e no processo de humanização da sociedade (CALDART, apud CARDOSO e ARAÚJO, 2012), 
se apropriando, para tal, da marca discursiva do campo. No entanto, quando se referem ao domínio do conhecimento científico pelos povos do campo para garantirem uma vida melhor ou se posicionarem frente a situações que envolvam questões éticas e culturais, não fica claro como seria essa apropriação.

Paniago et al (2014), propõem que "professores do campo construam conhecimentos relativos ao seu meio sociocultural, ambiental e contribuam para uma efetiva educação no/do campo, em que o no se refere a uma educação que ocorre no espaço dos alunos do campo e o do traduz a representação de um processo educativo vinculado às questões socioculturais desse espaço” (p. 180). Assim, as autoras assumem a expressão educação no/do campo para designar a soma de uma educação científica que ocorre no espaço dos alunos, com um processo educativo vinculado às questões socioculturais do campo.

As autoras defendem práticas escolares que envolvam a educação ambiental no sentido de aproximar o ensino da realidade dos alunos do campo e propõem que tanto a formação docente como as práticas educativas utilizem a pesquisa como ferramenta de ensino. Essa ferramenta possibilitaria refletir e intervir sobre situações práticas do cotidiano, além de contribuir para a construção de uma sociedade sustentável e para a relação do ensino com o trabalho e saberes do homem do campo.

Costa et al (2014) assumem que o ensino de ciências deve respeitar a realidade cultural dos povos do campo, pois, segundo as autoras, "uma prática pedagógica descompromissada com a problematização da realidade e sem o devido respeito à diversidade cultural fortalece processos de desumanização" (p. 164). As autoras se apropriam da voz de Roseli Caldart para definir a educação do campo e assim, assumem que para construir uma proposta educacional deve-se ir além dos conteúdos descontextualizados e valorizar os saberes oriundos das experiências, proporcionando uma formação voltada ao desenvolvimento de várias dimensões do ser humano. Para as autoras, é necessário que surjam novas alternativas pedagógicas para que o ensino de ciências, na perspectiva da educação do campo, possa convergir para uma ação educativa destinada à formação humana.

Podemos notar que nos três artigos, considerados enquanto enunciados, há construção híbrida do discurso, porém essa construção é realizada de diferentes maneiras. Cardoso e Araújo (2012) desenvolvem seu discurso trazendo vozes das perspectivas críticas do currículo, da crítica ao livro didático e a voz da educação do campo. Assim, o processo híbrido de construção do discurso das autoras é caracterizado pela mescla de vozes críticas que vão ao encontro da visão de autores da educação do campo. Por outro lado, Paniago et al (2014) constroem seu discurso sem priorizar a voz da educação do campo. A hibridização se dá quando os autores resgatam a voz da educação ambiental no sentido de aproximar o ensino de ciências da realidade dos alunos do campo.

Costa et al (2014) também trazem a voz da perspectiva que defende a educação do campo realizando assim um diálogo com essa área, além de terem a formação humana integral e a diversidade cultural rural como marcas do seu discurso.

\section{A educação rural nos artigos internacionais da área de educação em ciências}

Os artigos internacionais desenvolvem argumentos, críticas e propostas relacionando a educação em ciências com a educação rural. A maioria dos estudos 
é acerca da educação rural nos EUA e a forma com que os autores constroem seus argumentos é bem variada.

Dos onze trabalhos analisados, sete defendem a valorização da cultura local como uma forma de melhorar a educação científica nas escolas rurais. Avery e Hains (2016) examinam como o conhecimento científico é transmitido através de tradições orais entre gerações em uma comunidade rural, e consideram que levar essa forma de transmissão em conta ao ensinar ciências enriquece e torna diverso o currículo. Ao explorarem a complexidade dos provérbios orais que são compartilhados pelos idosos e examinarem suas raízes histórico-científicas, os autores afirmam ter descoberto uma riqueza de informações sobre as conexões socioculturais e ecológicas rurais e os macro e micro contextos dos quais surgem esses provérbios. Assim, apresentam um paradigma alternativo que incorpora o pluralismo do conhecimento local no ensino de ciências, buscando enriquecer as práticas pedagógicas na comunidade rural.

Após analisar provérbios orais de outra comunidade rural dos EUA, Stapleton (2016) também afirma que as tradições orais podem ser úteis para a inclusão das culturas e contextos das áreas rurais dentro da educação científica. A autora conclui que, pela comunidade rural dos EUA ser composta tanto por norte-americanos quanto por pessoas de outras regiões do mundo, a multiplicidade de culturas e vivências pode levar a uma aprendizagem científica rica, relacionada a diversos biomas, práticas agrícolas e culturais rurais. Abrams e Middleton (2016) ressaltam que é importante compreender quais são os recursos linguísticos sobre ciências exclusivos das comunidades rurais, mas, como as comunidades não são iguais, devese ir além e considerar os valores, crenças e práticas locais ao examinar quais são os melhores caminhos para melhorar o ensino de ciências. Assim, sugerem que para engajar a juventude rural na aprendizagem de ciências é necessário que se integre o conhecimento e prática científicas locais no processo educativo da sala de aula.

A valorização da realidade local é trazida como fator importante a ser levado em consideração quando se ensina ciências na zona rural. Borgerding (2016) argumenta que as comunidades rurais, em geral, são mais religiosas que as urbanas e, consequentemente, os jovens rurais também o são. Dessa forma, o ensino de alguns conceitos científicos, segundo a autora, pode representar um desafio aos docentes, já que esses conhecimentos podem contradizer ou enfrentar crenças religiosas. A autora realiza um estudo acerca do processo de ensino/aprendizagem da teoria da evolução, em uma escola de uma comunidade rural americana, e chega à conclusão de que os alunos enfrentam grandes tensões ao entenderem essa teoria, e cabe ao docente servir de mediador do processo. Para a autora, os professores devem reconhecer as perspectivas religiosas dos alunos e suas culturas domésticas e utilizá-las como gancho inicial para o ensino da teoria da evolução, bem como devem ajudar os alunos a entenderem a explicação científica dessa teoria, seu status científico, seu poder explicativo e aplicabilidade no dia a dia. Para ela, essa metodologia direciona os estudantes a aceitarem a teoria da evolução, ou empregar partes dessa teoria em suas visões pessoais.

Zimmerman e Weible (2016), por outro lado, afirmam que o conhecimento científico deve ser ensinado visando a ação, com unidades educacionais propostas a partir da realidade local. Por exemplo, quando uma comunidade rural articula o conhecimento teórico sobre a qualidade da água com sua realidade local. 
Segundo os autores, ao ensinar ciências partindo de um problema local, os alunos passam a compreender questões econômicas, culturais e ambientais ligadas àquele contexto, estimulando e preparando os jovens para administrarem, futuramente, a comunidade rural e seus problemas.

Eppley (2016) constrói seu texto concordando com os argumentos de Zimmermane e Weible (2016) e afirma que a educação científica ideal é a que envolve os estudantes em seu contexto ecológico, ao mesmo tempo em que os envolve com os contextos socioculturais e econômicos do local, pois, essa forma de educar cientificamente, auxilia o desmantelamento de obstáculos à justiça social na zona rural. Huffling et al (2016) inferem que uma das estratégias para o empoderamento dos jovens da zona rural é utilizar o ensino de ciências para olhar os problemas e a realidade local, promovendo um diálogo crítico acerca das estruturais sociais.

A estrutura educacional também aparece nos trabalhos, ao ser criticada por Fortunato (2016), que afirma que a padronização do ensino, imposta pelo sistema educacional norte-americano é danosa ao contexto rural, já que acaba valorizando algumas formas de conhecimento em detrimento de outras. Assim, o autor sugere que o ensino de ciências mostre diferentes visões acerca da mesma situação, o que poderá prover os estudantes com subsídios para criar argumentos e desenvolver suas próprias perspectivas.

Kingsolver (2016) direciona seu trabalho para a perspectiva de valorização da realidade local, se referindo às comunidades indígenas dos Apalaches dos EUA. Segundo a autora, essas comunidades possuem mais diversidade cultural do que a mídia tende a mostrar, e a valorização dessa diversidade ajuda no enfrentamento de estereótipos. Para aproximar o ensino de ciências da realidade local e valorizar os conhecimentos indígenas a autora sugere a abordagem de temas econômicos, políticos, geográficos, sociais, ambientais na prática pedagógica. Kassam et al (2016) afirmam que o ensino de ciências pode ser favorecido se aliarmos uma pedagogia crítica ao conhecimento local indígena e rural, além de acreditarem que essa mudança de perspectiva educacional pode inspirar mudanças de práticas educacionais e políticas públicas. Esses autores consideram que fugir das padronizações educacionais e proporcionar um ensino com diversidade ecológica e cultural forma cidadãos com diversidade cognitiva, enriquece o ensino de ciências e promove a preservação da própria cultura e do meio ambiente. LowanTrudeau (2016) apresenta dois casos emblemáticos ocorridos em territórios indígenas canadenses e uma parte de territórios norte-americanos (construção de um oleoduto e de um gasoduto) e defende que os educadores em ciências utilizem casos reais como oportunidades pedagógicas para suscitar o envolvimento e a exploração, pelos estudantes, de problemas locais das comunidades indígenas.

Os processos híbridos de construção discursiva dos autores internacionais se dão de diversas formas: Fortunato (2016), por exemplo, elabora seu enunciado através da hibridização da voz da educação em ciências e da voz crítica à estrutura educacional norte-americana, que valoriza a hegemonia de saberes. Avery e Hains (2016), Stapleton (2016) e Abrams e Middleton (2016) hibridizam o ensino de ciências e a diversidade cultural através da voz que defende a valorização e a utilização das linguagens e tradições orais locais em consonância com as práticas didáticas. A voz da diversidade cultural também aparece no enunciado de Kingsolver (2016) que defende 
a sua valorização para desconstrução de estereótipos e hibridiza a voz da educação em ciências e a voz de questões econômicas, políticas, geográficas, sociais e ambientais para aproximar a educação científica da realidade local. Kassam et al (2016) se voltam para a diversidade cultural e ecológica e ainda se apropriam da voz da pedagogia crítica, tecendo um discurso híbrido para desenvolver o ensino de ciências.

Vários autores trazem a voz da realidade local, porém de diferentes maneiras. Zimermann e Weible (2016) abordam uma situação específica para facilitar o processo de ensino/aprendizagem de ciências, enquanto Lowan-Trudeau (2016) traz casos ambientais como possibilidades pedagógicas para motivar os estudantes a explorarem problemas locais. Já Borgerding (2016) procura aproximar o ensino de ciências da realidade dos estudantes rurais por meio de uma perspectiva que respeita as diferentes crenças religiosas.

Outros autores aproximam a educação em ciências da realidade local através de perspectivas críticas, pois acreditam que essas podem auxiliar no alcance da justiça social. Huffling et al (2016) hibridizam o ensino de ciências e as questões da realidade através de um diálogo crítico acerca das estruturas sociais para valorizar a cultura local e estimular o pensamento crítico nos estudantes rurais. Eppley (2016) procura envolver os estudantes em suas realidades e examinar conflitos com discursos oficiais, construindo um discurso híbrido entre os contextos socioculturais e econômicos locais e o ensino de ciências, para oportunizar que seus alunos lutem por justiça social.

\section{DISCUSSÃO E CONSIDERAC̣ÕES FINAIS}

A pesquisa mostrou que embora a educação do campo esteja em pauta no Brasil pelo menos desde 2009 e se tenha iniciado grande número de cursos de licenciatura com ênfase em ciências desde 2012, este tema ainda não é recorrente nos periódicos nacionais de educação em ciências e nem significativamente representado nos periódicos internacionais pesquisados. Entretanto, isto não significa que essas pesquisas não estejam sendo realizadas e publicadas em outros meios, como anais de eventos ou periódicos de outras áreas de avaliação do Qualis CAPES, como a Educação, por exemplo.

A educação científica no âmbito da educação do campo está sendo construída discursivamente no Brasil através de enunciados responsivos a autores críticos e ao currículo e direcionados aos povos do campo, suas características, lutas e costumes, fazendo com que o conteúdo científico sirva às necessidades desses, e não o contrário. Neste sentido, é destacada na literatura nacional a questão da utilização da expressão "do campo" para marcar a luta pela afirmação do campo como um espaço social, cultural, histórico e socialmente singular. A denominação educação do campo em oposição à educação no campo é uma bandeira que busca distanciar essa educação de uma visão que imporia ao campo um caráter de inferioridade em relação ao meio urbano.

Outro ponto importante ressaltado por alguns artigos internacionais (EPPLEY, 2016; KINGSOLVER, 2016) é a necessidade de valorizar a singularidade do meio rural, sem tentar impor metodologias ou práticas que funcionam bem em escolas urbanas. Para outros autores, a padronização se dá através das políticas 
curriculares e exames nacionais e internacionais (FORTUNATO, 2016), discurso que se assemelha às críticas à prevalência da voz dos livros didáticos nos artigos brasileiros (CARDOSO e ARAÚJO, 2012; PANIAGO et al, 2014). O livro didático é pensado numa perspectiva que reproduz metodologias e práticas tradicionais em escolas urbanas, além de ser escrito e moldado na perspectiva da ciência ocidental moderna (CARDOSO e ARAÚJO, 2012), o que faz com que qualquer lugar do mundo tenha o mesmo ensino e que visões não eurocêntricas da ciência sejam rechaçadas e desvalorizadas no processo de ensino e aprendizagem. Esse discurso traz a voz da crítica ao currículo apropriada tanto pelos autores nacionais quanto pelos internacionais e nos leva a crer que os materiais didáticos voltados para a educação do campo deveriam ser desenvolvidos por pessoas que vivem a realidade do campo.

Considerando todo o conjunto de artigos e a diferença entre os contextos e culturas, foi possível perceber diferentes formas de hibridismo na apropriação da educação do campo pela pesquisa em educação científica. Em vários artigos (ZIMMERMAN e WEIBLE, 2016, STAPLETON, 2016; PANIAGO et al, 2014; BORGERDING, 2016; LOWAN-TRUDEAU, 2016; AVERY e HAINS, 2016), o conhecimento local é visto como importante, seja como parte de metodologias para ensinar o conteúdo científico seja para o ensino de temas da educação ambiental. Em outros (CARDOSO e ARAÚJO, 2012; COSTA et al, 2014; EPPLEY, 2016; ABRAMS e MIDDLETON, 2016; KASSAM et. al, 2016; KINGSOLVER, 2016; HUFFLING et al, 2016; FORTUNATO, 2016; STAPLETON, 2016), o conhecimento local é visto como fonte de empoderamento da comunidade e o conhecimento científico vai ser selecionado de modo a contribuir para esse empoderamento.

Apesar de todos os trabalhos proporem um ensino de ciências que valorize a realidade local, esse processo se concretiza de diferentes formas, no que diz respeito à apropriação do conhecimento científico e/ou do ensino de ciências. Conseguimos caracterizar três grupos: Alguns autores procuram trazer a realidade da comunidade do campo/rural para a sala de aula de ciências, sem modificarem o conjunto de conteúdos de ciências pré-selecionado (AVERY e HAINS, 2016; FORTUNATO, 2016, STAPLETON, 2016; ABRAMS e MIDDLETON, 2016; KASSAM et al, 2016; CARDOSO e ARAUJO, 2012; PANIAGO et al, 2014 e COSTA et al, 2014). Outros buscam realizar o ensino de ciências a partir de alguma questão local, ou seja, os conteúdos científicos são selecionados a partir de algum problema ou questão local (ZIMMERMAN e WEIBLE, 2016 e LOWAN-TRUDEAU, 2016). Também percebemos modificações das práticas de ensino de ciências no contato com a realidade do campo/rural, seja para se adequarem a uma realidade específica (BORGERDING, 2016), para favorecer a capacidade de luta por justiça social (EPPLEY, 2016), provocar o questionamento acerca da realidade e das estruturas sociais (HUFFLING et al, 2016) ou para desconstruir estereótipos (KINGSOLVER, 2016).

Os trabalhos que classificamos nos dois últimos grupos se aproximam do que consideramos adequado e que começamos a conceituar como educação científica do campo: uma educação afastada das visões capitalistas urbanocêntricas e da racionalidade técnica, e que relacione conceitos científicos a propósitos da educação do campo. Para tal, o currículo deverá ser construído por meio de discursos híbridos entre o conhecimento científico, os saberes locais e os interesses dos sujeitos do campo. Esperamos que essa reflexão possa representar avanços 
futuros para iniciativas de conceituação, de prática e de formação nas licenciaturas de educação do campo.

\section{REFERÊNCIAS}

ABRAMS, E.; MIDDLETON, M. Towards multidimensional approaches to research on rural science education. Cultural Studies of Science Education, v.12, p. 167-176, 2016. DOI 10.1007/ s11422-016-9748-2. Acesso em: 09 jan. 2017.

ARROYO, M. G.; CALDART, R. S.; MOLINA, M. C. Apresentação. In ARROYO, M. G.; CALDART, R. S.; MOLINA, M. C. Por uma Educação do Campo, Petrópolis: Vozes, 2004.

AVERY, L. M.; HAINS, B. J. Oral traditions: a contextual framework for complex science conceptslaying the foundation for a paradigma of promise in rural science education. Cultural Studies of Science Education, v. 12, p. 129-166, 2016. DOI 10.1007/s11422-016-9761-5. Acesso em: 09 jan. 2017.

BAKHTIN, M. M. Marxismo e filosofia da linguagem, 13ª Edição, São Paulo: Hucitec, 2009.

BAKHTIN, M. M. Estética da criação verbal, 6a Edição, São Paulo: Editora WMF Martins Fontes, 2011.

BAKHTIN, M. M. Teoria do romance I: A estilística, 1ª Edição, São Paulo: Editora 34, 2015.

BORGERDING, L. A. High school biology evolution learning experiences in a rural context: a case of and for cultural border crossing. Cultural Studies of Science Education, v. 12, p. 53-79, 2016. DOI 10.1007/s11422-016-9758-0. Acesso em: 09 jan. 2017.

BRASIL. [Constituição (1988)]. Constituição da República Federativa do Brasil de 1934. Brasília, DF: Presidência da República, [1935]. Disponível em: http://www.planalto.gov.br/ccivil_03/ constituicao/constituicao34.htm Acesso em: 27 jun. 2017.

BRASIL. Decreto - lei $\mathbf{n}^{\circ} 8.529$ de 02 de janeiro de 1946. Lei Orgânica do Ensino Primário. Disponível em: http://www2.camara.leg.br/legin/fed/declei/1940-1949/decreto-lei-8529-2janeiro-1946-458442-publicacaooriginal-1-pe.htm. Acesso em: 27 jun. 2017.

BRASIL. Decreto-lei $\mathbf{n}^{0} \mathbf{9 . 6 1 3}$ de 20 de agosto de 1946. Lei Orgânica do Ensino Agrícola. Disponível em: http://www2.camara.leg.br/legin/fed/declei/1940-1949/decreto-lei-9613-20agosto-1946-453681-publicacaooriginal-1-pe.htm. Acesso em: 27 jun. 2017.

BRASIL. Lei n ${ }^{\circ} \mathbf{9 3 9 4}$ de 20 de dezembro de 1996. Estabelece as diretrizes e bases da educação nacional. Disponível em http://www.planalto.gov.br/ccivil_03/leis/L9394.htm. Acesso em: 25 ago. 2017.

BRASIL. Resolução CNE/ CEB 1, de 3 de abril de 2002. Disponível em http://pronacampo.mec. gov.br/images/pdf/mn_resolucao_\%201_de_3_de_abril_de_2002.pdf. Acesso em: 25 ago. 2017.

CARDOSO, L. R.; ARAÚJO, M. I. O. Currículo de Ciências: professores e escolas do campo. Revista Ensaio- Pesquisa em Educação em Ciências, Belo Horizonte, v.14, n.2, p. 121-135, 2012.

COSTA, L. G., AIKAWA M. S., CUNHA, I. S. Ensino de Ciências: uma discussão na perspectiva da Educação do Campo. Areté - Revista Amazônica de Ensino de Ciências, Manaus, v. 7, n. 13, p. 161-169, 2014.

EPPLEY, K; Rural science education as social justice. Cultural Studies of Science Education, v. 12, p. 45-52, 2016. DOI 10.1007/s11422-016-9751-7. Acesso em: 09 jan. 2017. 
FERNANDES, B. M. Educação do Campo e Território Camponês no Brasil. In SANTOS, C. A. (org.) Por uma Educação do Campo: Campo, Políticas Públicas e Educação, Brasília: Incra/ MDA, 2008.

FORTUNATO, M. W. P. Advancing educational diversity: antifragility, standardization, democracy, and a multitude of education options. Cultural Studies of Science Education, v. 12, p.177-187, 2016. DOI 10.1007/s11422-016-9754-4. Acesso em: 09 jan. 2017.

HAGE, S.M. Movimentos sociais do campo e educação: referências para análise de políticas públicas de educação superior. Revista Eletrônica de Educação, São Carlos, v. 8, n.1, p. 133-150, 2014.

HUFFLING, L. D.; CARLONE, H. B.; BENAVIDES, A. Re-inhabiting place in contemporary rural communities: Moving toward a critical pedagogy of place. Cultural Studies of Science Education, v. 12, p. 33-43, 2016. DOI 10.1007/s11422-016-9756-2. Acesso em: 09 jan. 2017.

KASSAM, K. A. S.; AVERY, L. M.; RUELLE, M. L. The cognitive relevance of Indigenous and rural:Why is it critical to survival? Cultural Studies of Science Education, v. 12, p. 97-118, 2016. DOI 10.1007/s11422-016-9745-5. Acesso em: 09 jan. 2017.

KINGSOLVER, A. Practical resources for critical science education in rural Appalachia. Cultural Studies of Science Education, v. 12, p. 219-225, 2016. DOI 10.1007/s11422-016-9755-3. Acesso em: 09 jan. 2017.

KRASILCHIK, M. Reformas e Realidade O Caso do Ensino das Ciências. São Paulo em Perspectiva, São Paulo, v. 14, n. 1, p. 86-93, 2000.

LOWAN-TRUDEAU, G. Gateway to understanding: Indigenous ecological activism and education in urban, rural, and remote contexts. Cultural Studies of Science Education, v. 12, p. 119-128, 2016. DOI 10.1007/s11422-016-9746-4. Acesso em: 09 jan. 2017.

PANIAGO, R. N.; ROCHA, S. A.; PANIAGO, J. N. A pesquisa como possibilidade de ressignificação das práticas de ensino na escola do/no campo. Revista Ensaio - Pesquisa em Educação em Ciências, Belo Horizonte, v. 16, n. 1, p. 171-188, 2014.

RIBEIRO, M. Educação Rural. In CALDART, R. S.; PEREIRA, I. B.; ALENTEJANO, P.; FRIGOTTO, G. Dicionário da Educação do Campo, Rio de Janeiro: Expressão Popular, 2012.

STAPLETON, S. R. Oral traditions, changing rural landscapes, and Science education. Cultural Studies of Science Education, v. 12, p. 189-198, 2016. DOI 10.1007/s11422-016-9749-1. Acesso em: 09 jan. 2017.

VENDRAMINI, C. R. Os desafios do MST e da educação na atualidade brasileira. Perspectiva, Florianópolis, v. 31, n. 2, p. 505-525, 2013.

VENEU, A.A.; FERRAZ, G.; REZENDE, F. Análise de discursos no ensino de ciências: considerações teóricas, implicações epistemológicas e metodológicas. Ensaio - Pesquisa em Educação em Ciências, Belo Horizonte, v. 17, n. 1, p. 126-149, 2015.

VOLOSHINOV, V. N. A estrutura do enunciado. Tradução de Ana Vaz, para fins didáticos. Texto original publicado na revista Literatura Ucëba, v. 3. p. 65-87, 1930.

ZIMMERMAN, H. T.; WIEBLE, J. L. Learning in and about rural places: Connections and tensions between students' everyday experiences and environmental quality issues in their community. Cultural Studies of Science Education, v. 12, p. 7-31, 2016. DOI 10.1007/s11422-016-9757-1. Acesso em: 09 jan. 2017. 


\section{APÊNDICE A - PERIÓDICOS QUALIS/CAPES QUADRIÊNIO 2013/2016}

\begin{tabular}{|c|c|}
\hline Periódico & $\begin{array}{c}\text { Extrato de Avaliação no } \\
\text { Qualis/CAPES }\end{array}$ \\
\hline Ciência e Educação & A1 \\
\hline Cultural Studies of Science Education & A1 \\
\hline Educación Quimica & A1 \\
\hline Ensaio Pesquisa em Educação em Ciências & A1 \\
\hline Enseñanza de las Ciencias & A1 \\
\hline Interciencia & A1 \\
\hline International Journal of Science Education & A1 \\
\hline Journal of Science Education and Technology & A1 \\
\hline Physics Education & A1 \\
\hline Research in Science Education & A1 \\
\hline Revista Brasileira de Ensino de Física & A1 \\
\hline Revista de Educación de las Ciencias & A1 \\
\hline Revista Eureka & A1 \\
\hline Science \& Education & A1 \\
\hline Alexandria & A2 \\
\hline Amazônia-Revista de Educação em Ciências e Matemática & A2 \\
\hline Areté-Revista Amazônica de Ensino de Ciências & A2 \\
\hline Caderno Brasileiro de Ensino de Física & A2 \\
\hline Ciência e Cultura & A2 \\
\hline Enseñanza de las Ciencias de la Tierra & A2 \\
\hline Interfaces Científicas & A2 \\
\hline Investigações em Ensino de Ciências & A2 \\
\hline Latin American Journal of Phisicis Education & A2 \\
\hline Revista Electrónica de Enseñanza de las Ciencias & A2 \\
\hline Revista de Ensino de Ciências e Matemática & A2 \\
\hline Revista Brasileira de Ensino de Ciências e Tecnologia & A2 \\
\hline Revista Brasileira de Pesquisa em Educação em Ciências & $\mathrm{A} 2$ \\
\hline Revista Educação, Ciências e Matemática & A2 \\
\hline Revista Electrónica de Investigación en Educación en Ciencias & A2 \\
\hline
\end{tabular}




\section{NOTAS}

1 Roseli Caldart é integrante do Coletivo Nacional de Educação do Movimento dos Trabalhadores Rurais Sem Terra e do Movimento "Por uma Educação do Campo". A pesquisadora estuda questões sobre a educação do campo, movimentos sociais do campo e sua pedagogia e contribuiu com importantes títulos para a reflexão e pesquisa sobre a educação do campo, como: Dicionário da Educação do campo (2012), a coleção Por uma Educação do Campo (1999 - 2008) e Pedagogia do Movimento Sem Terra (2000).

Submetido em 25/03/2019

Aprovado em 16/12/2019

\section{Contato:}

Rua Engenheiro Sadi Castro, n. 860/303 - Sarandi CEP 91.130-060 - Porto Alegre, RS - Brasil 